\title{
Food deserts in Winnipeg, Canada: a novel method for measuring a complex and contested construct
}

\author{
Joyce Slater, PhD (1); Stefan Epp-Koop, MA (2); Megan Jakilazek, BSc (3); Chris Green, PhD (3)
}

This article has been peer reviewed.

\section{Abstract}

Introduction: "Food deserts" have emerged over the past 20 years as spaces of concern for communities, public health authorities and researchers because of their potential negative impact on dietary quality and subsequent health outcomes. Food deserts are residential geographic spaces, typically in urban settings, where low-income residents have limited or no access to retail food establishments with sufficient variety at affordable cost. Research on food deserts presents methodological challenges including retail food store identification and classification, identification of low-income populations, and transportation and proximity metrics. Furthermore, the complex methods often used in food desert research can be difficult to reproduce and communicate to key stakeholders. To address these challenges, this study sought to demonstrate the feasibility of implementing a simple and reproducible method of identifying food deserts using data easily available in the Canadian context.

Methods: This study was conducted in Winnipeg, Canada in 2014. Food retail establishments were identified from Yellow Pages and verified by public health dietitians. We calculated two scenarios of food deserts based on location of the lowest-income quintile population: (a) living $\geq 500 \mathrm{~m}$ from a national chain grocery store, or (b) living $\geq 500 \mathrm{~m}$ from a national chain grocery store or a full-service grocery store.

Results: The number of low-income residents living in a food desert ranged from 64574 to 104335 , depending on the scenario used.

Conclusion: This study shows that food deserts affect a significant proportion of the Winnipeg population, and while concentrated in the urban core, exist in suburban neighbourhoods also. The methods utilized represent an accessible and transparent, reproducible process for identifying food deserts. These methods can be used for costeffective, periodic surveillance and meaningful engagement with communities, retailers and policy makers.

Keywords: food desert, GIS, food security, Canada

\section{Introduction}

"Food deserts" have emerged over the past 20 years: residential geographic spaces, typically in urban settings, where low-income residents have limited or no access to retail food establishments with sufficient variety at affordable cost. ${ }^{1}$ They are spaces of concern for communities, public health authorities and researchers due to their potential negative impact on diet quality and quantity. Residents of food deserts may effectively be dependent on small retailers, such as convenience stores, with limited selection and typically higher prices, for the bulk of their food purchasing. Their situation is exacerbated since they may not have the financial resources to own a car, or have adequate alternative transportation means. ${ }^{2,3}$ The lack of full-service, fair-priced grocery stores in a community may therefore
Highlights

- Although "food deserts" are a contested concept, it is useful to measure and describe them to stimulate discussion about how to address food insecurity and inequity issues.

- In $2014,9 \%$ of the Winnipeg Health Region population was living in an urban food desert, defined as having low income and living $\geq 500 \mathrm{~m}$ from a national chain grocery store or a full-service grocery store.

- The majority of food desert neighbourhoods were concentrated in the downtown area of Winnipeg; however, there were several affected neighbourhoods in the outer suburbs.

- Simple and cost-effective methods using income, location of food stores, population counts and onthe-ground verification can defensibly identify the location and size of urban food deserts, and be used for ongoing surveillance.

- Failure to include local full-service grocery stores when identifying food deserts may lead to an overestimation of their size.

promote inequities by leaving residents at increased risk of compromised diet quality, negatively impacting long-term health. ${ }^{4-6}$

It is important to note, however, that no common definition of "food desert" exists, and the literature contains a variety of constructs, primarily based on the methodologies used, that vary greatly. ${ }^{7,8}$ Some 
authors question the usefulness of the food desert construct, arguing it obfuscates the priority issue of inadequate income, regardless of one's proximity to a full-service grocer. ${ }^{9}$ Others have attempted to incorporate this dimension using the concept of "food mirages"-neighbourhoods that have full-service stores, yet remain inaccessible to low-income residents because of lack of purchasing power. ${ }^{10,11}$ One may therefore conclude that food deserts are a contested concept, with constructs and methodologies continuing to emerge.

To date, the presence and characteristics of food deserts have been studied primarily in urban settings including Australia, the UK, the United States and Canada. ${ }^{12-16}$ Results of this research are equivocal. A review by Beaulac et al. ${ }^{17}$ found that clear disparities in food access exist by income and race in many municipalities in the United States, but not elsewhere. Food deserts have been identified in cities in Australia $^{12}$ and the UK; ${ }^{18}$ however, in the latter, the establishment of a full-service grocer did not alter residents' diets. ${ }^{19}$ Research from Canada indicates that some cities have food deserts, including London, Ontario, where low-income inner-city residents were shown to have the poorest access to supermarkets, ${ }^{20}$ and Gatineau, Quebec, where $7.5 \%$ of the population live with limited financial resources along with low access to healthy food. ${ }^{21}$ Low income is not always associated with poor food access, however. While more extensive food deserts have been found in some low-income Edmonton and Saskatoon neighbourhoods, others are located in areas with high access to grocery stores. ${ }^{22,23}$ Similar trends have been found in southern Ontario urban centres. ${ }^{15,24}$ These findings were confirmed in a recent review of Canadian food environments by Minaker et al., ${ }^{25}$ who concluded that food desert patterns were more pronounced in the United States than Canada, where many deprived urban neighbourhoods have access to healthy food as good as, in some cases better access than wealthier neighbourhoods.

Even within urban areas, different conclusions about the presence and characteristics of food deserts have been drawn. For example, three studies in the city of Montréal, Quebec, came to different conclusions. Apparicio and colleagues found that geographic accessibility of healthy food was not an issue, and therefore concluded that food deserts are not a problem in Montreal. ${ }^{26}$ Bertrand and colleagues concluded that a significant proportion of the population without vehicles had poor access to fruits and vegetables. ${ }^{27}$ Páez and colleagues, while not using the term "food deserts," found differential access to healthy food among poor Montréal residents depending upon where they lived. ${ }^{2}$ The diverse and often contradictory nature of these findings are due to the diverse methods used to identify and define food deserts, including the spatial methods deployed, whether access to transportation was factored in, the type and variety of retail stores used in the analysis, the granularity and complexity of the methods used, and whether inputs and results were validated through appropriate qualitative methods.

A significant challenge with many food desert studies is that their complex methods and detailed inputs, often requiring significant primary data collection, may make them difficult and expensive to replicate. For example, Luan's work, ${ }^{24}$ while producing a very detailed assessment of the Waterloo food environment, utilized a number of complex variables and methods (e.g. "relative healthy food access," spatio-temporal trends and hierarchical modelling) that would be difficult and expensive to replicate. In addition, complex methods may hinder effective knowledge translation of results to nonacademic audiences, as methods that are difficult to explain may have less credibility with community members and policy makers. Further, given the dynamic nature of the contemporary foodscape, where retailers routinely leave or enter a community, it is critical to be able to update food desert analyses regularly so they are current and relevant; complex, resource-intensive methods may make this challenging to do in a timely fashion.

Despite the contested nature of food deserts, and the lack of consensus on the appropriate methods to measure and describe them, they nonetheless have become an important concept that facilitates discussion, debate and negotiation within communities, and between communities and policy makers, about how to address food insecurity in the context of modern foodscapes. ${ }^{28}$ The term food desert has achieved "brand recognition" in the fields of community development and public health, even if there is disagreement on what constitutes a food desert, which is useful for focussing attention on issues around food environments and food insecurity. Consequently, the purpose of this study was to demonstrate the feasibility of implementing a reproducible method of identifying food deserts using minimal resources, and with data easily available in the Canadian public health context. As onerous methods are beyond the scope of the vast majority of public health departments in Canada, this approach provides a pragmatic model for implementing foodscape surveillance in applied public health settings.

\section{Methods}

The study took place in the Winnipeg Health Region, which is made up of the City of Winnipeg and two adjacent rural municipalities. The Winnipeg Health Region is located in the central Canadian province of Manitoba, and in 2014 had a population of 736000 .

We used three data sources (described below) to create two food desert scenarios (Table 1) based on proximity to two categories of retail food stores: national chain grocery stores and full-service grocery stores. "National chain grocery stores" were defined as large, full-service grocery stores that had stores in Manitoba as well as other provinces. "Full-service grocery stores" were defined as large, local grocery stores (not national chains) carrying

TABLE 1

Scenarios used to determine food deserts in Winnipeg, Manitoba, Canada

\begin{tabular}{l|l}
\hline Food desert scenario 1 & $\begin{array}{l}\text { A dissemination block in the lowest income quintile, and } \\
\text { Dissemination block centroid } \geq 500 \text { metres from a national chain } \\
\text { grocery store. }\end{array}$ \\
\hline Food desert scenario 2 & $\begin{array}{l}\text { A dissemination block in the lowest income quintile, and } \\
\text { Dissemination block centroid } \geq 500 \text { metres from a national chain } \\
\text { grocery store OR a full-service grocery store. }\end{array}$ \\
\hline
\end{tabular}


a good selection of self-serve fresh fruits and vegetables (i.e. more than potatoes, onions and bananas, and not prepackaged), fresh meat and dairy products at reasonable prices (i.e. close to national chain prices), as assessed by local public health dietitians participating in the study, who had excellent knowledge of local stores, food costs and store characteristics. Dietitians were provided with lists of candidate stores, and judged whether they were appropriately classified; they also identified stores that were missing from the list, and any stores that had subsequently closed.

First, we constructed a database of all national chain and full-service grocery stores currently operating in the Winnipeg Health Region. The data was initially culled from the Winnipeg and area telephone Yellow Pages (not digital). Community dietitians and community facilitators from the Winnipeg Regional Health Authority verified and refined the initial database of food stores to ensure it reflected what was in their community.

Second, we used the 2011 Canadian census data at the dissemination-area level to classify the 5500 dissemination blocks within the Winnipeg Health Region into quintiles by average household income, using the income cut-offs defined by the Manitoba Centre for Health Policy. ${ }^{29}$ Each income quintile contains approximately $20 \%$ of the Winnipeg population (Table 2). In our study, average household income is used as a population-level indicator of food purchasing power as well as a proxy indicator of potential car ownership. Dissemination blocks were attributed with the income quintile classification of the dissemination area they fell into. Dissemination areas are the smallest geographic unit for which Statistics Canada

TABLE 2

Winnipeg Health Region income ranking by quintile, Winnipeg, Manitoba, Canada

\begin{tabular}{ccc} 
Quintile & $\begin{array}{c}\text { Average household income of lowest } \\
\text { earning dissemination area within } \\
\text { quintile (\$) }\end{array}$ & $\begin{array}{c}\text { Average household income of highest } \\
\text { earning dissemination area within } \\
\text { quintile (\$) }\end{array}$ \\
\hline 1 & 14772 & 49506 \\
2 & 49509 & 63475 \\
3 & 63513 & 78890 \\
4 & 78957 & 98953 \\
5 & 98963 & 343154 \\
\hline
\end{tabular}

Data source: Statistics Canada. 2011 Census of Population. disseminates detailed census information; in the Winnipeg Health Region there are 1150 dissemination areas. Dissemination blocks are smaller than dissemination areas (there are approximately five dissemination blocks for each dissemination area), but do not contain detailed census data.

Third, we derived total population counts from the 2014 Manitoba population health registry, ${ }^{30}$ with population data geocoded to the dissemination block-level using sixdigit postal codes.

Fourth, to identify the two food desert scenarios, the geodesic distance (the shortest distance "as the crow flies") from the centroid of each of the 5500 dissemination blocks to the nearest national chain or full-service grocery store was calculated. We chose this method as it improves replicability without greatly affecting results. We used a distance of 500 metres or less as a reasonable "walkable" distance to a grocery store, a distance that has been used by other researchers. ${ }^{4,31}$ Since the weather in Winnipeg is very cold, with snow on the ground for over one-third of the year from November until early April, we assessed that 500 metres was a reasonable distance for people to walk with the additional burden of groceries, and possibly children.

Finally, we classified dissemination blocks as food deserts under the two scenarios outlined in Table 1 . The total population residing in all identified food deserts within the Winnipeg Health Region was then calculated by summarizing the population count in those dissemination blocks classified as food deserts. All calculations were undertaken in Epi Info version 3.5.4 $4^{32}$ using automated scripts, and tabular outputs exported into ArcGIS $10.2^{33}$ for mapping.

\section{Results}

Figure 1 shows the distribution of dissemination blocks by income quintile within the Winnipeg Health Region. While the majority of low-income geographies are located in the downtown core of Winnipeg, additional low-income areas are located in the outer suburbs.

Figure 2 shows the location of food deserts in the Winnipeg Health Region under scenario 1, which used the distance to the nearest national chain grocery store in low-income neighbourhoods. This method classified a substantial cluster of dissemination blocks as food deserts in the downtown area of Winnipeg, with a smaller number of dissemination blocks fitting the food desert criteria scattered throughout the suburbs. Under scenario 1, there were 104335 people $(14.49 \%$ of the population) living in food deserts in the Winnipeg Health Region in 2014.

Figure 3 shows the location of food deserts under scenario 2, which used the distance to either a national chain grocery store or a full-service grocery store in lowincome neighbourhoods. As shown, the inclusion of full-service grocery stores in the analysis results in a substantially smaller number of dissemination blocks being classified as food deserts in the downtown area compared to scenario 1 . Most of the food desert locations in the outlying suburbs identified in scenario 1 , however, remain in scenario 2 . Under scenario 2, there were 64574 people $(9.1 \%$ of the population) living in food deserts in the Winnipeg Health Region in 2014.

\section{Discussion}

The results of this study suggest that food deserts exist within the Winnipeg Health Region and affect a significant proportion of the population. This study implemented two food desert scenarios, based upon proximity to national chain grocery stores only, or to either national chain or local full-service grocery stores, among residents living in low-income areas. Under the best-case scenario, where we used proximity to either national chain or local full-service grocery stores, it is estimated that $9 \%$ (almost 1 in 10) of Winnipeg residents live in a food desert. If proximity only to a national chain food store was used, almost $15 \%$ (or 1 in 8 ) of Winnipeg residents (104 335) were identified as living in a food desert. The maps show that 
FIGURE 1

Average household income by income quintile, Winnipeg Health Region, 2011

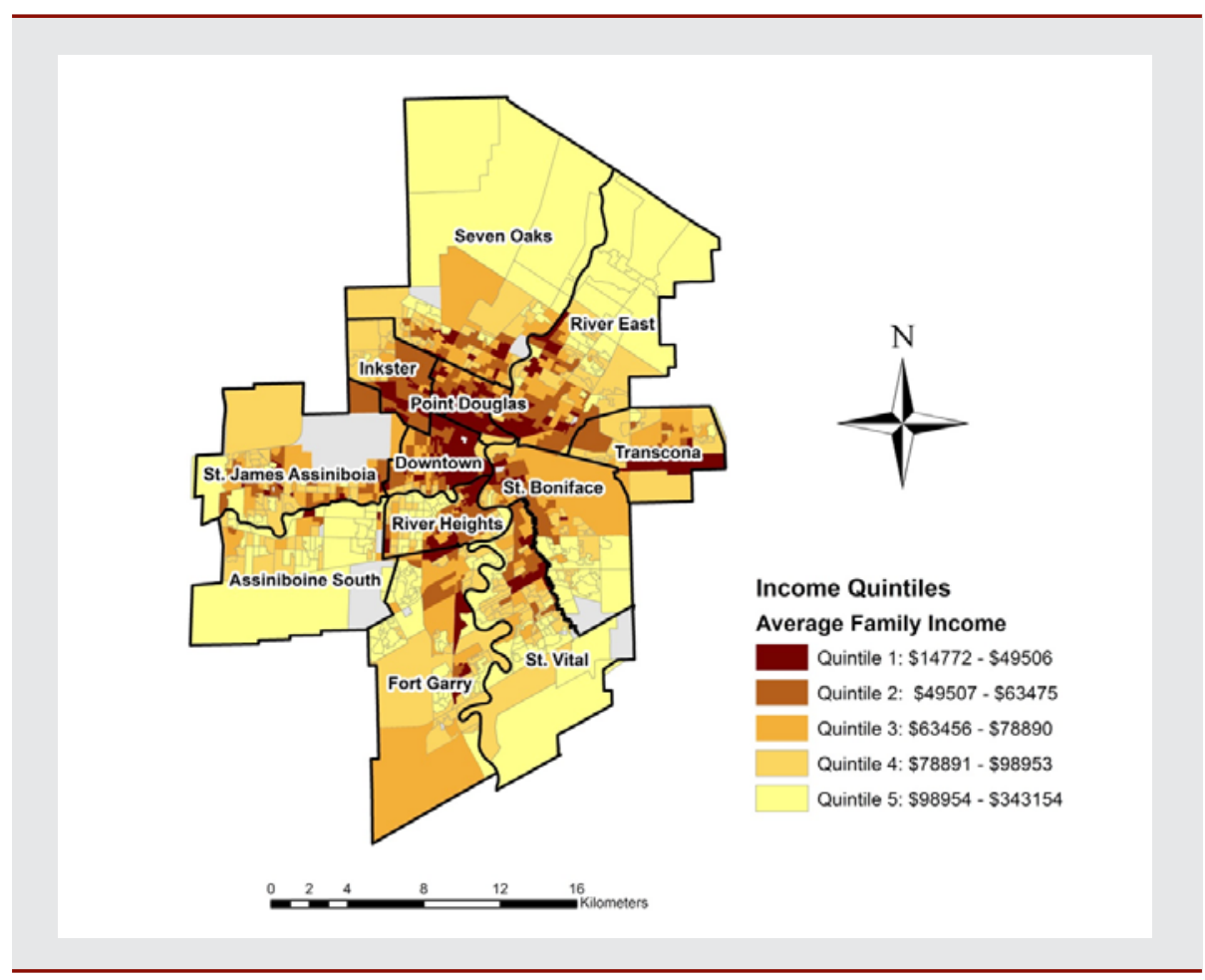

Data source: Statistics Canada. 2011 Census of Population.

FIGURE 2

Food desert scenario 1: food deserts in the Winnipeg Health Region, based only on proximity to national chain grocery store

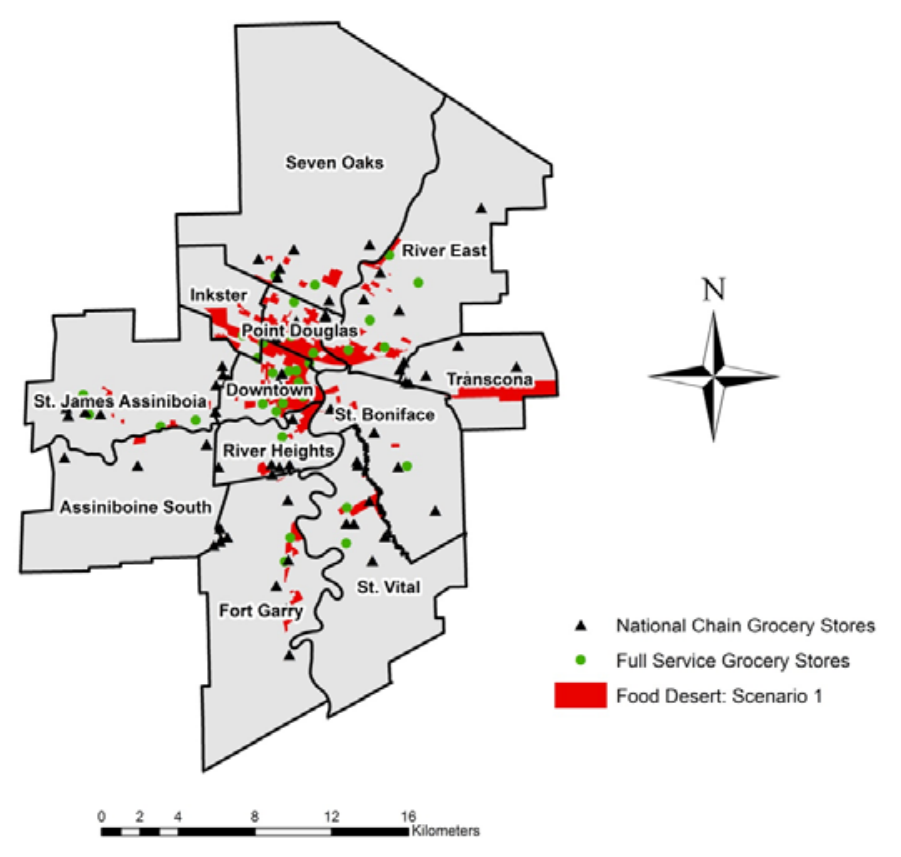

while food deserts are concentrated in the downtown area of the Winnipeg, pockets of suburban food deserts also exist. These results are consistent with results found in some other Canadian cities, which identified a significant number of low-income residents with poor access to healthy food sources. . $^{10,20,21,23}$

Winnipeg has one of the largest populations of urban poor in Canada, with $17.5 \%$ of the population living in lowincome circumstances, compared with $9 \%$ of the overall population in 2010. ${ }^{34}$ More specifically, the downtown residential areas in Winnipeg most highly affected by food deserts, Downtown and Point Douglas, had median household incomes in 2010 of $\$ 36298$ and $\$ 39614$ respectively, compared to $\$ 58503$ for the Winnipeg Health Region as a whole. ${ }^{35}$ A low income reduces transportation options, and inadequate access to affordable transportation has been shown to be a barrier to accessing sufficient, healthy food., ${ }^{2,3}$ Lowerincome households have less access to personal vehicles and drive less than their higher-income counterparts. ${ }^{36,37}$ Lack of easy access to affordable and nutritious food coupled with low income creates a double burden for a significant number of Winnipeggers living in food deserts. They must therefore either rely on alternate food sources such as convenience stores, food banks and low-cost fast food options such as "dollar" pizza and other bargain fast food outlets; or rely on taxis (which are expensive) or personal networks (which can be inconvenient and unreliable), if available, for rides to and from larger grocery stores.

The observation that food deserts persisted in suburban neighbourhoods, even when accounting for full-service grocery stores, indicates that these neighbourhoods are mainly serviced by large national chain stores. This is consistent with trends observed in grocery retailing, where larger, corporate chain stores are displacing smaller chains and independent stores in what Bedore refers to as a "scaled-up, disembedded [food retail] industry that now dominates the landscape."38

\section{Strengths and limitations}

This study makes a unique contribution to the food and built environment literature in terms of methodology. First, this study has demonstrated that a relatively simple, reproducible approach that uses only 
FIGURE 3

Food desert scenario 2: food deserts in the Winnipeg Health Region, based on proximity to either a national chain grocery store or a full-service grocery store

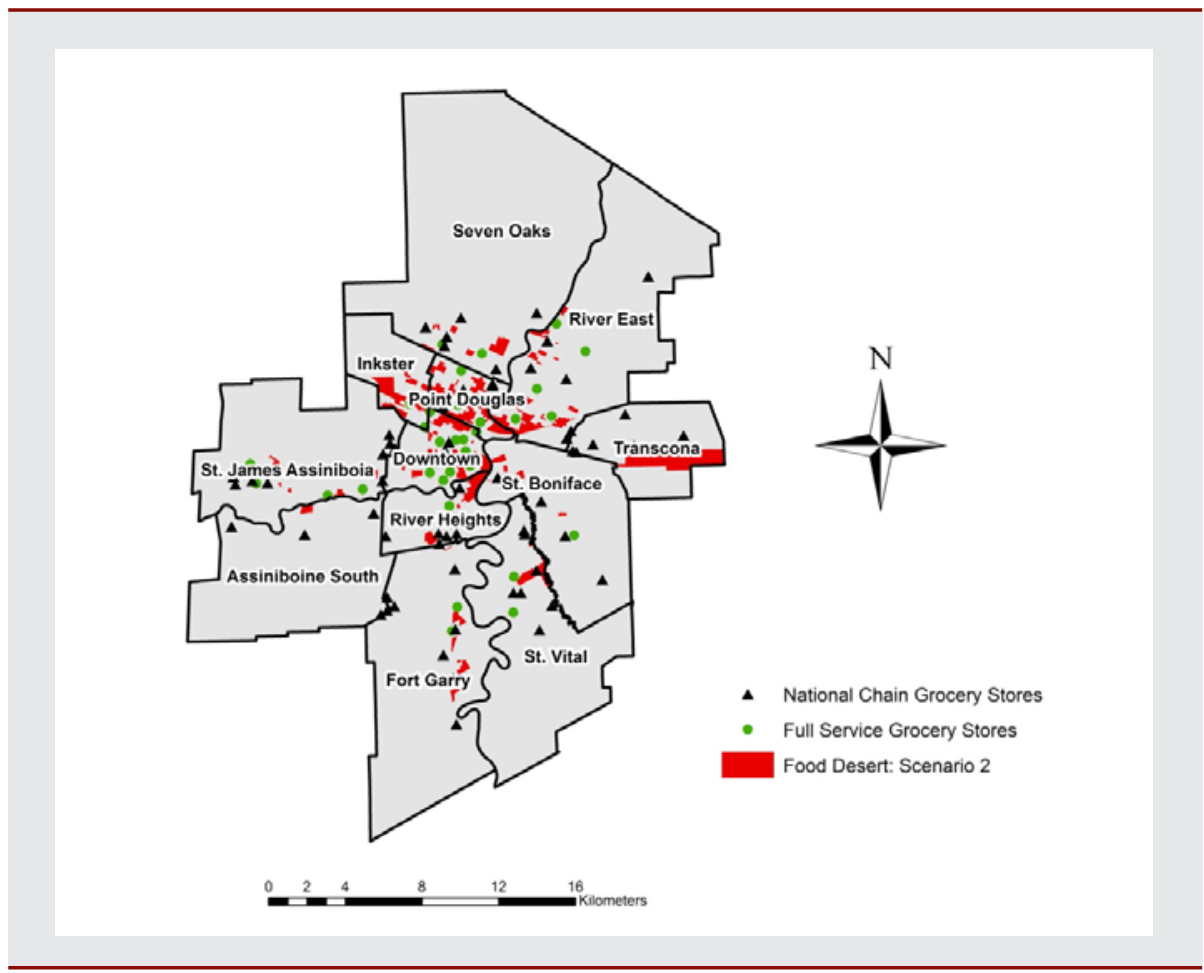

three data inputs (food store locations, household income and population counts) can be used to generate a defensible food desert analysis for a large urban centre. This pragmatic approach is especially important as public health departments do not typically have the resources to engage in complex food environment analyses on an ongoing basis. Furthermore, we have found that the relative simplicity of our methods has facilitated knowledge mobilization with key community stakeholders including community nutritionists, food activists and policy makers.

Second, this study has demonstrated that all calculations for the identification of food deserts can be implemented using automated scripts in Epi Info software with tabular outputs that can be easily imported into ArcGIS for mapping. The advantage of this approach is that when new updates are required (i.e. when a food store opens or closes down, or if there is an interest in exploring the impact of different proximity inputs), the food desert analysis can be updated quickly and easily. This actually occurred during our study period (several food stores closed, and two opened), and we were able to re-run our analysis and produce updated maps and population estimates with minimal effort and resources.

Third, this study has demonstrated that using only proximity to large national chain food stores, as has been undertaken in other food desert analyses in Canada, ${ }^{21}$ may in fact result in an overestimation of the size of food deserts and the population affected. In many downtown areas, smaller local grocery stores may play an extremely important role in providing easy access to a wide range of affordable food products. As shown in this study, taking into account proximity to local full-service grocery stores in additional to national population affected by food deserts in the Winnipeg Health Region by $38 \%$, from 104335 to 64574 individuals.

Our study has a number of limitations that must be taken into account when interpreting its results. First, we assigned income ecologically to individuals based upon residence in a low-income dissemination area. It is possible that there may be high-income individuals in our study living in low-income dissemination areas who do not experience economic and transportation barriers to accessing an adequate range of healthy food, and this chain stores decreased the estimate of the may have resulted in an overestimation of the size of the population living in food deserts in the Winnipeg Health Region. This overestimation may be offset, however, by low-income individuals living in high-income dissemination areas who did not get counted as living in a food desert in our study.

Second, our study used geodesic distance ("as the crow flies") instead of network distance (distance one would actually have to travel along a street network) to estimate the travel distance to the nearest food store. Although this may have added some inaccuracies to our distance calculations, the error this introduced was likely minimal in the downtown neighborhoods of Winnipeg where the majority of the food deserts were identified. In downtown Winnipeg, there is a very tight street network structure (i.e. short blocks, many cross-streets), which means that geodesic and network distances would likely be similar since residents can pick many straightforward routes to get from their residence to a food store. In suburban neighbourhoods this may have led to more misclassification due to less tightly structured street networks.

Third, our study did not specifically take into account public transportation options when identifying food deserts. However, we believe that our use of household income is a good proxy of people's financial ability to easily transport themselves to the nearest food store by car, taxi or bus. In Winnipeg, bus fare is expensive (especially if a parent is also paying for accompanying children; for example, $1 \times$ $\$ 2.70$ adult fare plus $2 \times \$ 2.20$ child fare adds up to $\$ 14.20$, round trip) and the existence of a local bus route would not necessarily increase access to a distant food store (especially also if one is bringing home a large volume of groceries). Furthermore, in Winnipeg, bus routes from central neighbourhoods to larger stores in suburban areas are often sporadic and inconvenient.

A final limitation of this study was that no structured metric (e.g. formal costing or objective assessment of food availability at the store level) was implemented in order to classify stores. As indicated earlier, candidate stores were initially identified through the local Yellow Pages, with validation by community dietitians working for the local regional health authority. 
Formally evaluating the characteristics of the retail food environment (cost and variety) is challenging and resource intensive; this may explain why other food desert studies have restricted their analyses only to the obvious large national chain food stores that are easy to identify. Resources permitting, we suggest that future studies should attempt to more formally evaluate cost and variety characteristics of local stores, with quantifiable criteria. We would argue, however, that in this study the verification undertaken by local public health dietitians is defensible given their intimate knowledge of local communities, and the limited resources available. Future studies should examine the impacts of food deserts on dietary behaviour and health outcomes, as well as residents' experiences of living in food deserts.

\section{Conclusion}

This study has demonstrated that the presence of food deserts in Winnipeg, a city with persistently high rates of poverty, affects nearly one in 10 citizens. We found that areas of food deprivation and low income were clustered in the "core" or centre of the city; however, there were affected communities in suburban areas. The novel methods utilized in our study represent a transparent, reproducible process for routine surveillance and meaningful engagement with communities, retailers and decision makers. The inclusion of local full-service grocers in addition to national chain grocery stores provides a more realistic assessment of food desert existence. While adequate income is a priority for addressing food insecurity, assessing the prevalence of food deserts and presenting the data in an accessible manner also allows for knowledge mobilization and the addition of other important sociodemographic and foodscape data into the analysis. Our food desert outputs were formatted as spatial files, meaning that food desert layers may in the future be overlaid with other relevant data in both static maps and interactive mapping applications such as Google Earth, ${ }^{39}$ providing a powerful tool for engaging stakeholders.

\section{Acknowledgements}

The authors would like to acknowledge the invaluable assistance of the Winnipeg Regional Health Authority public health dietitians in completion of this study.

\section{Conflicts of interest}

The authors have no conflicts of interest.

\section{Authors' contributions}

JS, CG and SE contributed to the study concept, data analysis and writing of the manuscript. MJ contributed to data analysis. All authors assisted in interpretation of results, manuscript revision and approved the final version.

\section{References}

1. Cummins S, Macintyre S. "Food deserts"-evidence and assumption in health policy making. BMJ. 2002; 325(7361):436-8.

2. Páez A, Mercado RG, Farber S, Morency C, Roorda M. Relative accessibility deprivation indicators for urban settings: definitions and application to food deserts in Montréal. Urban Stud. 2010;47(7):1415-38.

3. Tsang S, Holt AM, Azevedo E. An assessment of the barriers to accessing food among food-insecure people in Cobourg, Ontario. Chronic Dis Can. 2011;31(3):121-8.

4. Wrigley N. "Food deserts" in British cities: policy context and research priorities. Urban Stud [Internet]. 2002 [cited 2017 Mar 14];39(11):2029-40. Available from: http://usj.sagepub .com/content/39/11/2029.full.pdf

5. Moore L V, Diez Roux A V, Nettleton JA, Jacobs DR. Associations of the local food environment with diet quality-a comparison of assessments based on surveys and geographic information systems: the multi-ethnic study of atherosclerosis. Am J Epidemiol. 2008;167(8):917-24.

6. Chen D, Jaenicke EC, Volpe RJ. Food environments and obesity: household diet expenditure versus food deserts. Am J Public Health. 2016;106(5):881-8.

7. Shaw HJ. Food deserts: Towards the development of a classification. Geogr Ann Ser B Hum Geogr. 2006;88(2): 231-47.

8. Walker RE, Keane CR, Burke JG. Disparities and access to healthy food in the United States: a review of food deserts literature. Health Place. 2010; 16(5):876-84.
9. McEntee J. Highlighting food inadequacies: does the food desert metaphor help this cause? Br Food J. 2009;111(4):349-63.

10. Wiebe, K, Distasio J, Shirtliffe, R. Confronting the illusion: developing a method to identify food mirages and food deserts in Winnipeg [Internet]. Winnipeg (MB): The University of Manitoba; 2016. Available from: http://winnspace.uwinnipeg.ca/ handle/10680/1205

11. Breyer B, Voss-Andreae A. Food mirages: geographic and economic barriers to healthful food access in Portland, Oregon. Health Place. 2013; 24:131-9.

12. Coveney J, O'Dwyer LA. Effects of mobility and location on food access. Health Place. 2009;15(1):45-55.

13. Macdonald L, Ellaway A, Ball K, Macintyre S. Is proximity to a food retail store associated with diet and BMI in Glasgow, Scotland? BMC Public Health [Internet]. 2011;11(1): 464. Available from: http://dx.doi .org/10.1186/1471-2458-11-464

14. Alviola PA, Nayga RM, Thomsen MR, Wang Z. Determinants of food deserts. Am J Agric Econ. 2013;95(5): 1259-65.

15. Polsky JY, Moineddin R, Glazier RH, Dunn JR, Booth GL. Foodscapes of southern Ontario: neighbourhood deprivation and access to healthy and unhealthy food retail. Can J Public Health. 2014;105(5):e369-e375.

16. Chen $\mathrm{H}^{-}$. J, Wang Y. The changing food outlet distributions and local contextual factors in the United States. BMC Public Health [Internet]. 2014;14:42. doi: 10.1186/1471-2458 $-14-42$.

17. Beaulac J, Kristjansson E, Cummins S. A systematic review of food deserts, 1966-2007. Prev Chronic Dis. 2009 [cited 2017 Mar 16];6(3):A105. Available from: https://www.ncbi.nlm .nih.gov/pmc/articles/PMC2722409/

18. Whelan A, Wrigley N, Warm D, Cannings E. Life in a "Food Desert." Urban Stud [Internet]. 2002 [cited 2017 Mar 16];39(11):2083-100. Available from: http://journals.sagepub .com/doi/abs/10.1080/004209802200 0011371 
19. Wrigley N, Warm D, Margetts B, Whelan A. Assessing the Impact of Improved Retail Access on Diet in a "Food Desert": A Preliminary Report. Urban Stud. 2002;39(11):2061-82.

20. Larsen K, Gilliland J. Mapping the evolution of "food deserts" in a Canadian city: supermarket accessibility in London, Ontario, 1961-2005. Int J Health Geogr [Internet]. 2008 [cited 2017 Mar 14];7(1):16. Available from: http://www.ij-healthgeographics .com/content/7/1/16

21. Gould AC, Apparicio P, Cloutier MS. Classifying neighbourhoods by level of access to stores selling fresh fruit and vegetables and groceries: identifying problematic areas in the city of Gatineau, Quebec. Can J Public Health. 2012;103(6):e433-e437.

22. Smoyer-Tomic KE, Spence JC, Amrhein C. Food deserts in the prairies? Supermarket accessibility and neighborhood need in Edmonton, Canada. Prof Geogr. 2006;58(3):307-26.

23. Cushon J, Creighton T, Kershaw T, Marko J, Markham T. Deprivation and food access and balance in Saskatoon, Saskatchewan. Chronic Dis Inj Can. 2013;33(3):146-59.

24. Luan H, Law J, Quick M. Identifying food deserts and swamps based on relative healthy food access: a spatio-temporal Bayesian approach. Int J Health Geogr [Internet]. 2015 [cited 2017 Mar 14];14(1):37. doi: 10.1186 /s12942-015-0030-8.

25. Minaker LM, Shuh A, Olstad DL, Engler-Stringer R, Black JL, Mah CL. Retail food environments research in Canada: a scoping review. Can J Public Health [Internet]. 2016;107: 5344. doi: 10.17269/cjph.107.5344.

26. Apparicio P, Cloutier MS, Shearmur R. The case of Montréal's missing food deserts: evaluation of accessibility to food supermarkets. Int J Health Geogr [Internet]. 2007 [cited 2017 Mar 16];12;6:4. doi: 10.1186/1476 $-072 \mathrm{X}-6-4$.

27. Bertrand L, Thérien F, Cloutier MS. Measuring and mapping disparities in access to fresh fruits and vegetables in Montréal. Can J Public Health. 2008;99(1):6-11.
28. Nicholson, Katie; Marcoux J. Buying groceries a long trek for family in Winnipeg food desert [Internet]. CBC News. 2015 Dec 02 [cited 2016 Oct 15]. p. 1. Available from: http:// www.cbc.ca/news/canada/manitoba /buying-groceries-a-long-trek-for -family-in-winnipeg-food-desert-1 .3345126

29. Manitoba Centre for Health Policy. Concept: income quintile ranking procedure [Internet]. Winnipeg (MB): Manitoba Centre for Health Policy. 2002 [cited 2016 Oct 10]. Available from: http://mchp-appserv.cpe .umanitoba.ca/viewConcept.php ?conceptID $=1164$

30. Rady Faculty of Health Sciences. Manitoba population health research data repository data list [Internet]. Rady Faculty of Health Sciences. 2017 [cited 2016 Oct 5]. Available from: http://umanitoba.ca/faculties/health _sciences/medicine/units/chs /departmental_units/mchp/resources /repository/datalist.html

31. Furey S, Strugnell C, Mcilveen H. An investigation of the potential existence of "food deserts" in rural and urban areas of Northern Ireland. Agric Human Values. 2001;18(4):447-57.

32. Epi Info version 3.5.4 (Centers for Disease Control and Prevention, Atlanta, GA, USA); 2012. Available from: https://www.cdc.gov/epiinfo /index.html

33. ArcGIS version 10.2 (Environmental Systems Research Institute [ESRI], Redlands, CA, USA); 2012.

34. Statistics Canada. Persons in low income after tax [Internet]. Ottawa (ON): Statistics Canada; 2012 [modified 2013 Jun 27; cited 2016 Oct 5]. Available from: http://www.statcan .gc.ca/tables-tableaux/sum-som/101 /cst01/famil19a-eng.htm?sdi = low income

35. City of Winnipeg. Census information: 2011 census-City of Winnipeg neighbourhood profiles [Internet]. Winnipeg (MB): City of Winnipeg; 2013 [modified 2016 Oct 11; cited 2016 Oct 6]. Available from: http:// winnipeg.ca/census/2011
36. Berube A, Deakin E, Raphael S. Socioeconomic differences in household automobile ownership rates: implications for evacuation policy [Internet]. Washington (DC): The Brookings Institution; 2006 [cited 2017 Apr 28]. Available from: http://socrates.berkeley .edu/ raphael/BerubeDeakenRaphael .pdf

37. Statistics Canada. Survey of household spending, 2013 [Internet]. Ottawa (ON): Statistics Canada; 2013 [modifed 2015 Dec 21; cited 2017 Aug 3]. Available from: http://www.statcan .gc.ca/daily-quotidien/150122/dq150122b -cansim-eng.htm

38. Bedore M. Geographies of capital formation and rescaling: a historical-geographical approach to the food desert problem. Can Geogr. 2013; 57(2):133-53.

39. Google Earth [Internet]. Mountain View (CA): Google, Inc.; 2016. Available from: https://www.google.com /earth/ 